\title{
VARIABILIDAD EN LA UTILIZACIÓN DE PIGMENTOS EN ENTIERROS HUMANOS DEL HOLOCENO TARDÍO EN LA CUENCA SUPERIOR DEL RÍO SANTA CRUZ (PATAGONIA ARGENTINA)
}

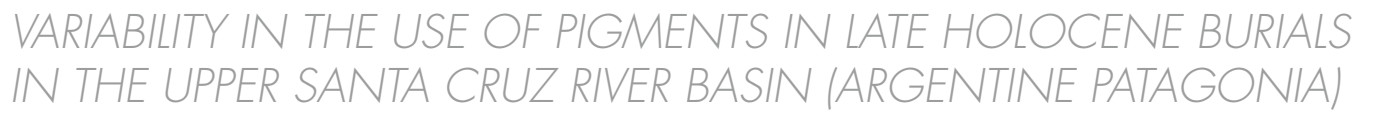

\author{
Nora Viviana Franco*, Ana lucía \\ GuARIDO * * TERESITA MONTENEGRO * * * \\ \& PABLO AMBRÚSTOLO****
}

\begin{abstract}
El objetivo de este trabajo es analizar la existencia de cambios en la forma de utilización de pigmentos en dos sitios en los que se han realizado entierros múltiples en la cuenca superior del río Santa Cruz, a comienzos y finales del Holoceno Tardío. Se efectuaron análisis macroscópicos, con microscopio binocular y de difracción de rayos $\mathrm{X}$. Los resultados obtenidos sugieren la existencia de un cambio en la forma de aplicación de pigmentos entre ca. 3600 y 430 años AP, lo que se suma a las evidencias ya existentes referidas a variaciones en la selección de espacios para realizar las inhumaciones y a la utilización de termoalteración sobre los restos humanos.
\end{abstract}

Palabras clave: Patagonia, pigmentos, entierros humanos, Holoceno Tardío

This paper analyzes changes in pigment use for two multiple burial sites of the Upper Santa Cruz River Basin, dated at the beginning and end of the Late Holocene. Macroscopical, binocular microscope and XRD analyses were performed. The results obtained suggest that the way pigments were applied changed between ca. 3600 and $430 \mathrm{BP}$. These findings can be added to the existing evidence of changes in the selection of burial locations and the thermoalteration of human remains.

Key words: Patagonia, pigments, human burials, Late Holocene

\section{INTRODUCCIÓN}

La cuenca superior del río Santa Cruz ha sido objeto de investigaciones desde 1991 (por ejemplo, Belardi et al. 1992; Franco et al. 1999; Borrero \& Franco 2000). Sin embargo, no fue hasta recientemente que se recuperaron restos humanos, gracias al aviso por parte de pobladores locales acerca de su existencia. En el momento del hallazgo, estos se encontraban en estado de riesgo por factores naturales y/o culturales (cf. Mehl \& Franco 2009; Franco et al. 2010).

El objetivo de este trabajo es entonces analizar la existencia de cambios en la forma de utilización de pigmentos en dos entierros múltiples en la cuenca superior del río Santa Cruz, uno correspondiente a inicios y otro, a finales del Holoceno Tardío. Esperamos que este análisis, unido a los cambios registrados en las formas de inhumación de los cuerpos (Franco et al. 2010) y al tratamiento de los restos (Guarido 2013), pueda contribuir a la comprensión de los cambios en el comportamiento de los cazadores-recolectores en este espacio durante el mencionado período.

* Nora Viviana Franco, ConiceT-Universidad de Buenos Aires, Saavedra 15, $5^{\circ}$ piso, C. A. B. A. (C. P. 1083), Argentina, email: nvfranco2008@gmail.com

* Ana Lucía Guarido, Universidad de Buenos Aires, Facultad de Filosofía y Letras, Saavedra 15, $5^{\circ}$ piso, C. A. B. A. (C. P. 1083), Argentina, email: analucia.guarido@gmail.com

*** Teresita Montenegro, ConicET (Facultad de Ciencias Exactas y Naturales) y Universidad de Buenos Aires, Argentina, email: mon@gl.fcen.uba.ar * Pablo Ambrústolo, ConICET-Museo de Ciencias Naturales La Plata-UNLP, Paseo del Bosque S/N (C. P. 1900), Argentina, email: pambrustlo@hotmail.com 
Los restos más antiguos analizados aquí corresponden al sitio Río Bote 1, localizado en la margen derecha del curso inferior del río homónimo, que desemboca en el curso superior del río Santa Cruz, en una cota de $215 \mathrm{~m}$, aproximadamente (fig. 1). Este sitio fue afectado por un cambio en el curso del río, que dejó expuesta su secuencia sedimentaria (cf. Mehl \& Franco 2009). En el mismo se recuperaron restos correspondientes a un número mínimo de 10 individuos, ocho de los cuales fueron datados entre ca. 3800 y $3620 \pm 25$ años AP (UGAMS7535) (Franco et al. 2010) (fig. 2). Esta inhumación incluye individuos adultos y subadultos (Salvarredy \& Guarido 2012). El análisis se centralizará aquí en tres individuos recuperados en la base de las estructuras cavadas, datados en ca. 3740 AP (Franco et al. 2010), que se encontraban sobre una capa de cenizas y carbones (Franco 2008). Los huesos analizados con difracción de rayos $\mathrm{X}$ de estos tres individuos indicaron que habían sido sometidos a alteraciones térmicas entre $600^{\circ} \mathrm{C}$ y $750^{\circ} \mathrm{C}$ (Montenegro et al. 2010). Por otra parte, los estudios referidos a la distribución de cambios de coloración ósea atribuidos a alteración térmica, que se compararon con el patrón propuesto por Symes y colaboradores (2008), sugieren que los tres individuos presentan signos de combustión que habría sido realizada en el sitio, cuando los cuerpos poseían aún tejido blando (Guarido 2013).

Entierros con características formales similares a los de Río Bote 1, aunque con menos individuos, han sido localizados más hacia el sur, en el espacio comprendido entre el río Santa Cruz y el estrecho de Magallanes (Bird 1983; Prieto 1991, 1993-1994; L'Heureux \& Barberena 2008). Los mismos poseen cronologías comprendidas entre ca. 3900 y 3500 AP e involucran también adultos y subadultos (Prieto 1991; Hedges et al. 1992 en Massone 1996; L'Heureux \& Barberena 2008; L'Heureux \& Amorosi 2010). En algunos casos poseen pigmento y se ha sostenido la existencia de combustión de los restos humanos sobre base macroscópica, es decir, los investigadores observaron cambios de coloración de

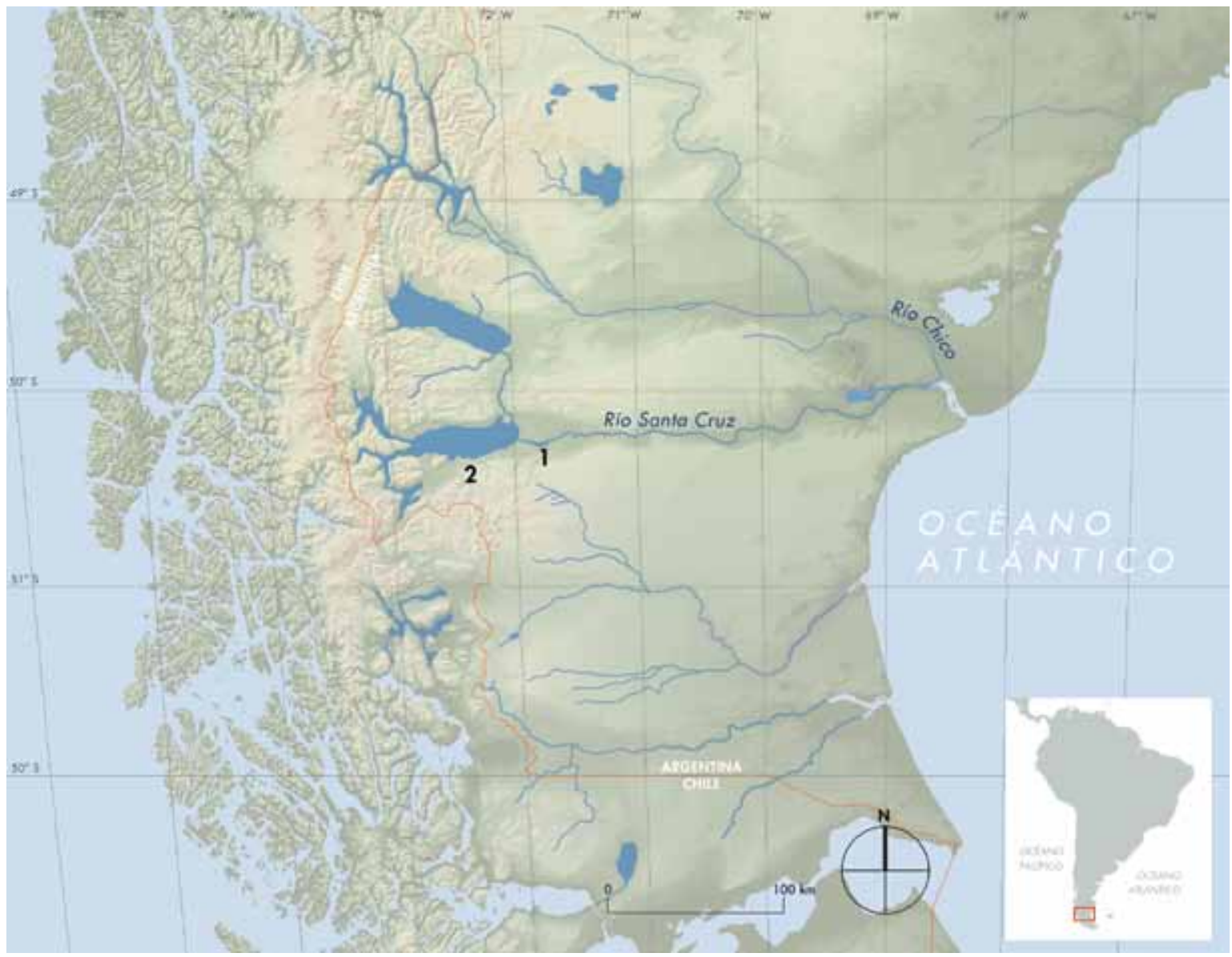

Figura 1. Localización de los sitios de entierro analizados: 1-Río Bote 1; 2-Huyliche 1.

Figure 1. Location of the burial sites analyzed: 1-Rí Bote 1; 2-Huyliche. 


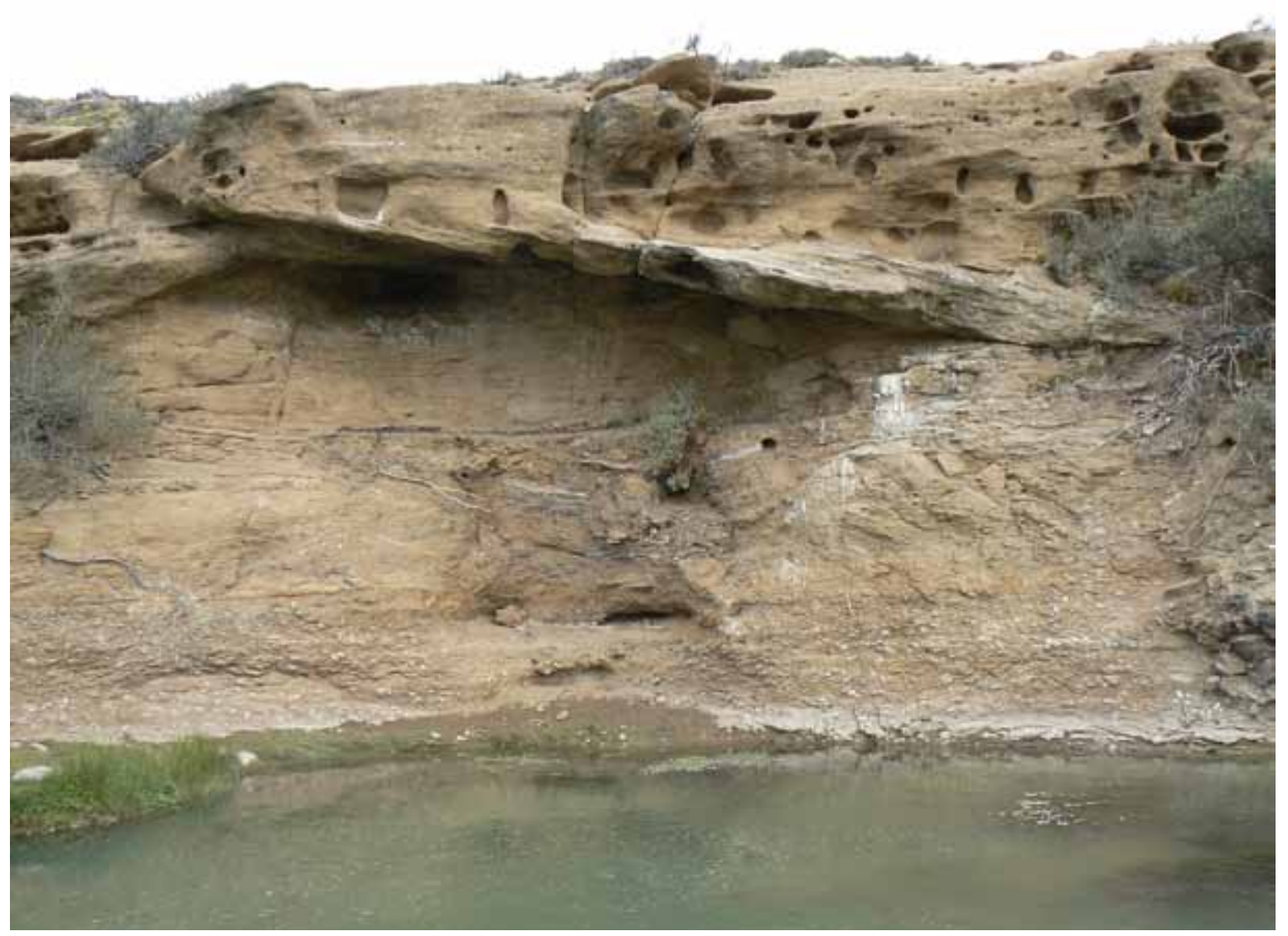

Figura 2. Vista del sitio Río Bote 1 al momento del hallazgo en 2007.

Figure 2. View of Río Bote 1 at the time of discovery in 2007.

la superficie ósea que interpretaron como alteraciones térmicas (Prieto 1991; L'Heureux \& Amorosi 2010).

El otro caso tratado en este trabajo es el sitio Huyliche 1, ubicado en el cerro homónimo, en una cota de altura de ca. $850 \mathrm{~m}$, al sur de la cuenca superior del río Santa Cruz, en cercanías de la ciudad de El Calafate (fig. 1). Se trata de un entierro múltiple, en un lugar con muy buena visibilidad, en una estructura que comúnmente se conoce como "chenque" (fig. 3). ${ }^{1}$ Ha sido fechado en ca. 430 AP (Franco et al. 2011). Este entierro contenía los restos de por lo menos seis individuos adultos y subadultos, que en algunos casos se encontraban en posición primaria, pero también había restos aislados (Franco et al. 2010). Las observaciones de campo indican que, en este caso, se había depositado pigmento sobre los cuerpos, los sedimentos y las rocas que cubrían el chenque. Al sudoeste de este espacio se detectó la presencia de un chenque en Cerro Guido (Morano Büchner et al. 2009). Contenía los restos de siete individuos (adultos y subadultos) y fue reutilizado recurrentemente entre $c a$. 1155 y 495 AP (Morano Büchner et al. 2009).
A diferencia de estos ejemplos, más hacia el sur se han identificado otras formas de entierro para las mismas cronologías. Sería el caso, por ejemplo, de Cerro Johnny, en el campo volcánico de Pali Aike, en el que un individuo -en el que se observó la utilización de colorantes- fue depositado en el interior de una pequeña cueva (Martinic 1976). Se han hallado también entierros bajo rocas al aire libre aunque, en esta ocasión, en cotas bajas. En algunos casos también presentan colorante rojo, como por ejemplo en San Gregorio 11 en cercanías del estrecho de Magallanes y Juni Aike, en el campo volcánico de Pali Aike (Massone et al. 19851986; Gómez Otero 1991; Aguilera \& Grendi 1996). Al norte del río Santa Cruz se encontraron evidencias de entierros en chenques con presencia de pigmentos en el curso inferior del río Ibáñez (Chile), con fechados de ca. 370 AP (Reyes 2002). A su vez, en el lago Salitroso se detectaron cuatro casos de entierros en chenque con pigmentos colocados sobre los restos humanos, dos de los cuales fueron fechados entre ca. 350 y 390 AP (Tessone et al. 2005). 


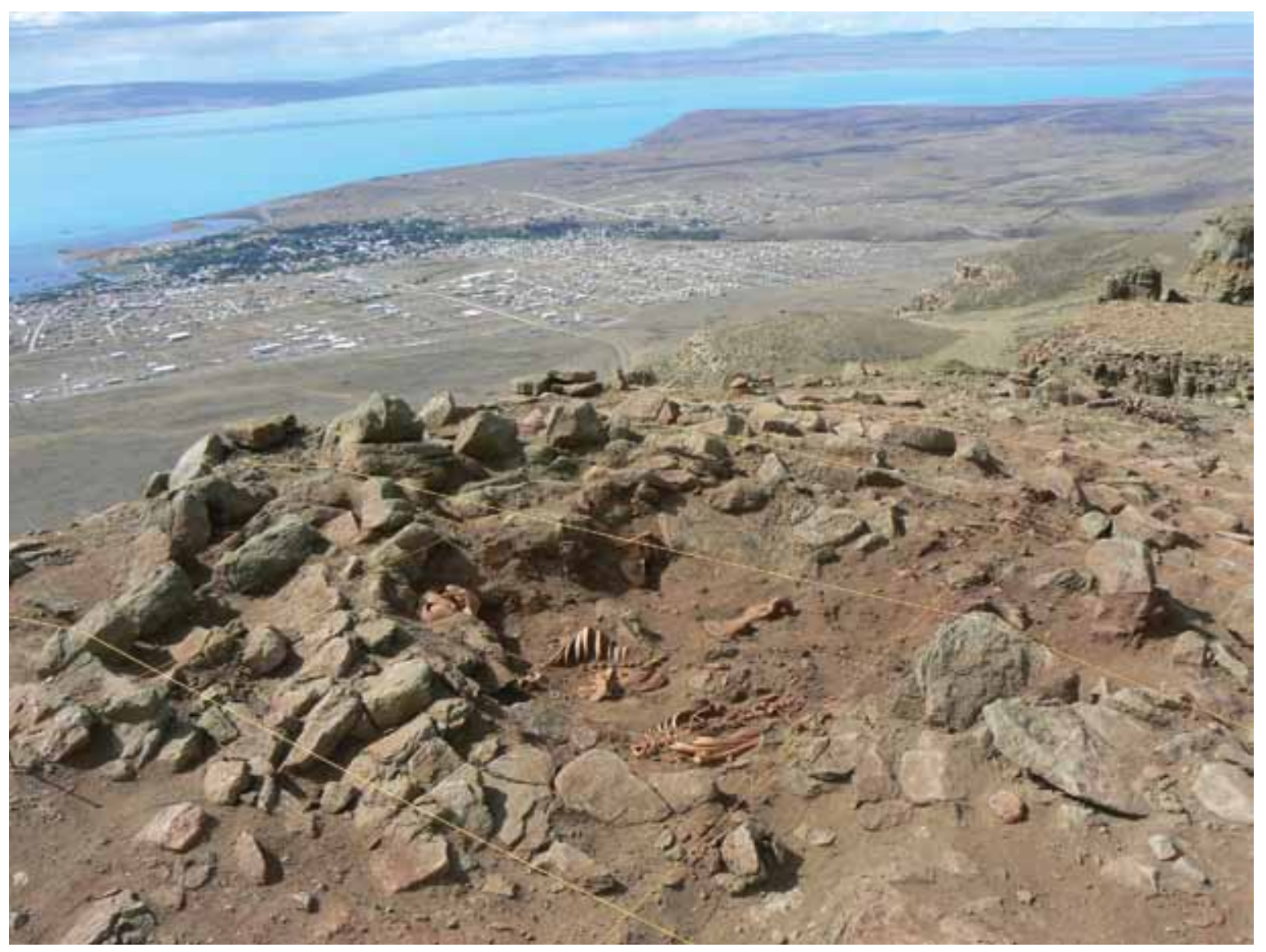

Figura 3. Vista del sitio Huyliche 1, al fondo se observan el lago Argentino y la ciudad de El Calafate. Figure 3. View of Huyliche 1 site, with Lago Argentino and the city of El Calafate in the distance.

En lo que se refiere al contexto regional de estos entierros, cabe señalar que aquellos datados entre $c a$. 3800 y 3620 AP en Río Bote 1, corresponden a un lapso en que los espacios más occidentales de esta área, al sudoeste de lago Roca, han sido atribuidos a la ocupación efectiva del área sobre la base de los fechados obtenidos en distintos sitios arqueológicos y las características del registro arqueológico lítico (Franco 2002, 2004). Por su parte, los correspondientes a Huyliche 1 pertenecen a un lapso temporal posterior a la Anomalía Climática Medieval (Stine \& Stine 1990; Stine 1994), para el que se ha postulado un abandono o reposicionamiento de las poblaciones humanas (cf. Borrero \& Franco 2000).

\section{METODOLOGÍA}

Para dar cuenta de las variaciones en la forma de aplicar los pigmentos, se realizaron análisis y tomas de muestras en campo y en laboratorio. En campo se registró la presencia de lo que fue interpretado preliminarmente como pigmento, tomándose muestras de sedimento con fines comparativos, tanto en el sector adyacente a los restos humanos como no adyacente. Los restos humanos recuperados fueron fotografiados.

El análisis posterior en laboratorio incluyó la observación macroscópica de lo que había sido interpretado preliminarmente como pigmento en los restos humanos y en el sedimento, el estudio de las muestras mediante microscopio binocular y el análisis de difracción por rayos $\mathrm{X}$.

Los sedimentos adyacentes a los cuerpos fueron observados con microscopio binocular con la finalidad de determinar, en primera instancia, la presencia de material colorante. En las muestras que resultaron fértiles en este contenido, se determinó, utilizando el mismo instrumental óptico, el porcentaje de sustancia colorante por método de comparación visual con patrones habitualmente utilizados en descripciones petrográficas. La naturaleza del material colorante se identificó mediante el análisis de difracción de rayos X, 
tanto de los sedimentos seleccionados como del material óseo. Para este análisis, la selección de las muestras óseas humanas se concentró solamente en aquellos fragmentos que se habían separado naturalmente del resto del hueso, eligiéndose fracciones pequeñas que no afectarían la reconstrucción del hueso, en caso de ser necesaria. Debido a que los óseos son destruidos durante el análisis, se tomaron múltiples fotografías de cada fragmento. También se tomaron muestras de la sustancia roja que se encontraba adherida en los huesos, extrayéndola con ayuda de un cepillo y una espátula plástica, para evitar contaminar la muestra.

El material -fragmentos óseos y sedimentos- fue molido en mortero de ágata y tamizado a malla 200. Los análisis de difracción se realizaron en el Instituto de Química y Física de los Materiales, Medio Ambiente y Energía (INQUIMAE) de la Facultad de Ciencias Exactas y Naturales (FCEN), Universidad de Buenos Aires (UBA) con difractómetro Siemens D 5000 y en el Laboratorio de Difracción de Rayos X, CIGA, INTEMIN, SEGEMAR, utilizando difractómetro Philips, modelo X'Pert MPD, con radiación de $\mathrm{Cu}-\mathrm{K} \alpha$, a $40 \mathrm{Kv} / 40 \mathrm{~mA}$, y colimadores de divergencia de $1^{\circ}$, de recepción de $0,1 \mathrm{~mm}$ y monocromador secundario de grafito. En ambos laboratorios el patrón de difracción fue tomado para un rango de $2 \theta$ entre $4^{\circ}$ y $70^{\circ}$ en pasos de $0,01^{\circ} / 7 \mathrm{~s}$ utilizando portamuestra circular y giratorio, de fondo cero. El análisis de los datos se llevó a cabo mediante el programa High Score Plus de Panalytical con la base de datos PDF del ICDD Año 2001. Tanto el instrumental como el programa fueron operados por personal idóneo de sendos laboratorios.

En este análisis, los datos se obtienen en forma de un patrón de difracción que representa la estructura cristalina de cada mineral, ya sea que este se encuentre en una mezcla mineral o aislado. La identificación se realiza a través de la comparación del diagrama obtenido con la base de datos del equipo o bibliografía pertinente (fichas JCPDS) (Bayliss et al. 1993). La interpretación de los resultados fue realizada por la Dra. T. Montenegro, autora del presente trabajo.

\section{RESULTADOS}

Sintetizaremos aquí los resultados obtenidos tanto en campo como en laboratorio para cada uno de los sitios bajo análisis.

\section{Observaciones en campo}

Las observaciones realizadas en campo tendían a sustentar la aplicación de pigmento sobre los cuerpos en el caso de Rio Bote 1, no observándose presencia de los mismos en los sedimentos adyacentes (figs. 4-7). En el caso del sitio Huyliche 1, el pigmento se encontraba tanto sobre los cuerpos, como sobre las rocas que lo cubrían y sobre los sedimentos (fig. 8).

\section{Análisis de gabinete}

Los análisis macroscópicos

Estos análisis indicaron que los tres individuos examinados en Río Bote 1 tenían presencia de pigmento rojo en la mayoría de sus restos, aunque las observaciones realizadas a ojo desnudo indicaban que no estaba distribuido homogéneamente en todos los huesos. En el caso del individuo $\mathrm{J}$, los pigmentos rojizos se encontraban en mayor abundancia en el cráneo, aunque casi todos los elementos recuperados presentaban una coloración rojiza a simple vista. En el caso del individuo I se recuperó un bajo número de elementos debido a la acción de la erosión previa al hallazgo. La mayoría también presentaba coloración rojiza. En el caso del individuo $\mathrm{H}$, la concentración de sustancia rojiza era mucho mayor en el cráneo que en cualquiera de los demás elementos, si bien la mayoría de los huesos identificados tenían una coloración rojiza o rosada. En cualquiera de los tres casos de individuos analizados, se detectó que la sustancia rojiza no se presentaba homogéneamente en la superficie de todo el hueso, sino que se generaban puntos de concentración y áreas sin pigmento o con muy poco.

Los individuos recuperados en Huyliche 1 presentan, en todos los casos, una coloración rojiza sobre las superficies óseas, tanto en el caso de individuos en su posición anatómica como en los restos aislados. En este caso, la presencia de pigmento es más homogénea sobre toda la superficie y solo se observó una concentración mayor en uno de los cráneos recuperados.

Los análisis mediante microscopio binocular

Las observaciones en lupa binocular mostraron diferencias en los porcentajes de hidróxidos y óxidos de hierro en los sedimentos de los dos entierros. Se analizaron cuatro muestras en el caso de Río Bote 1 y cinco en el caso de Huyliche 1.

Como puede verse, en el caso de Río Bote 1 tres de las cuatro muestras de sedimentos analizadas tienen menos del 10\% de hidróxidos e óxidos de hierro; en el caso de Huyliche 1, tres de las cinco muestras de sedimento presentan más de un $40 \%$ de compuestos oxidados de hierro. 


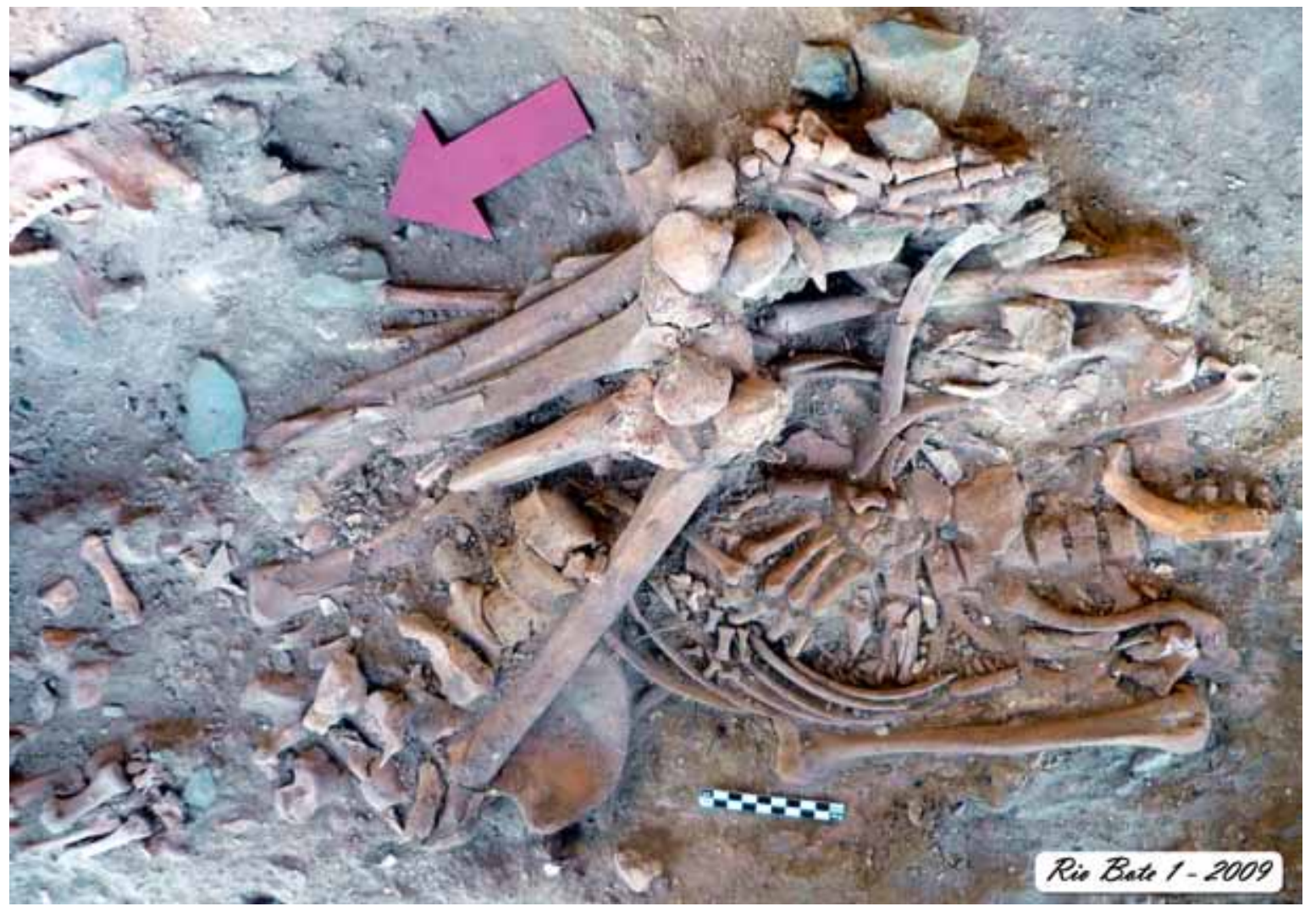

Figura 4. Río Bote 1, individuo $\mathrm{H}$.

Figure 4. Rí Bote 1, individual $\mathrm{H}$.

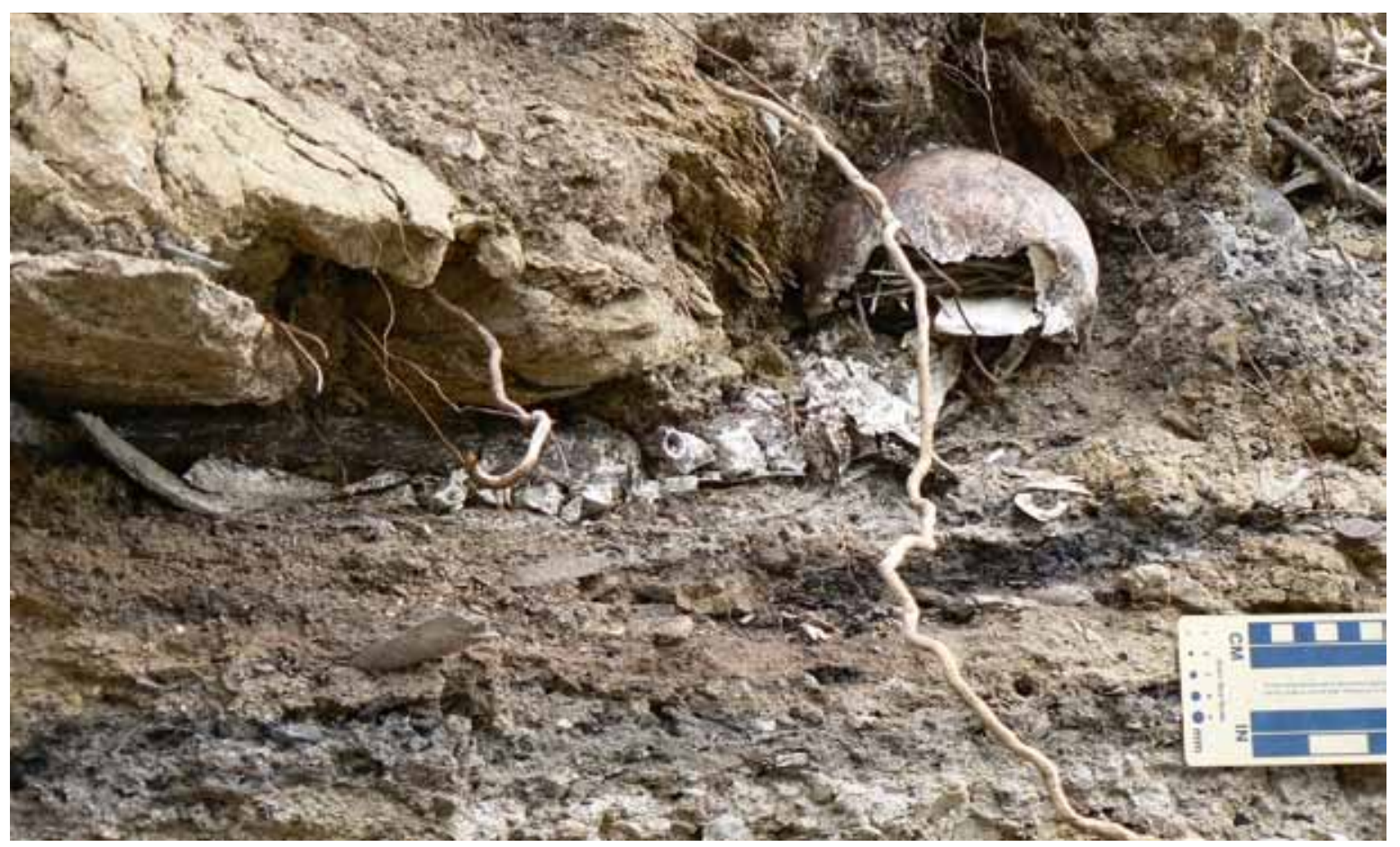

Figura 5. Río Bote 1, individuo J, vista desde el perfil.

Figure 5. Río Bote 1, individual J, side view. 


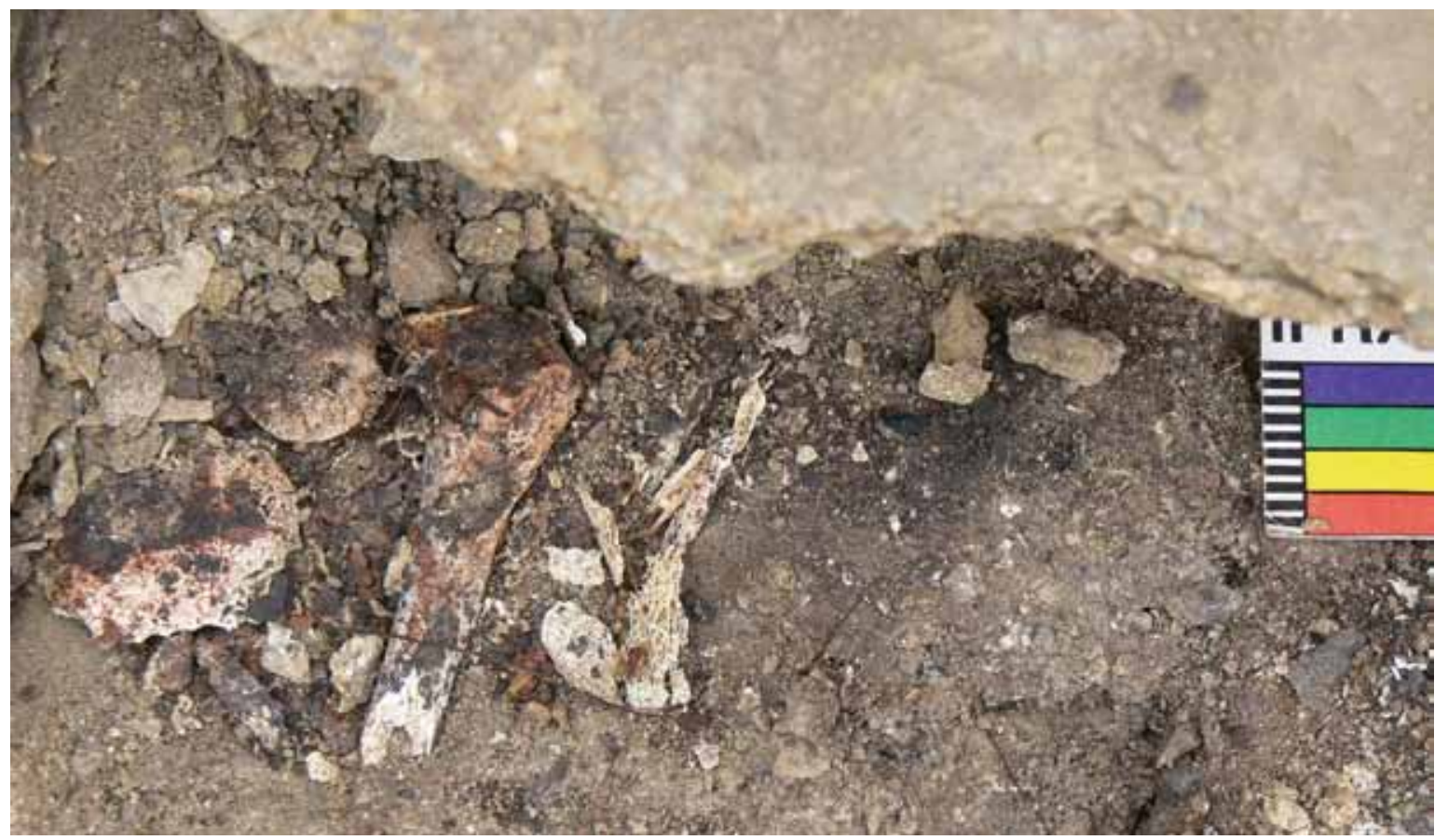

Figura 6. Río Bote 1. Se observa el individuo I a la izquierda y el J a la derecha de la imagen.

Figure 6. Río Bote 1. Individual I can be seen on the left and individual J on the right of the photo.

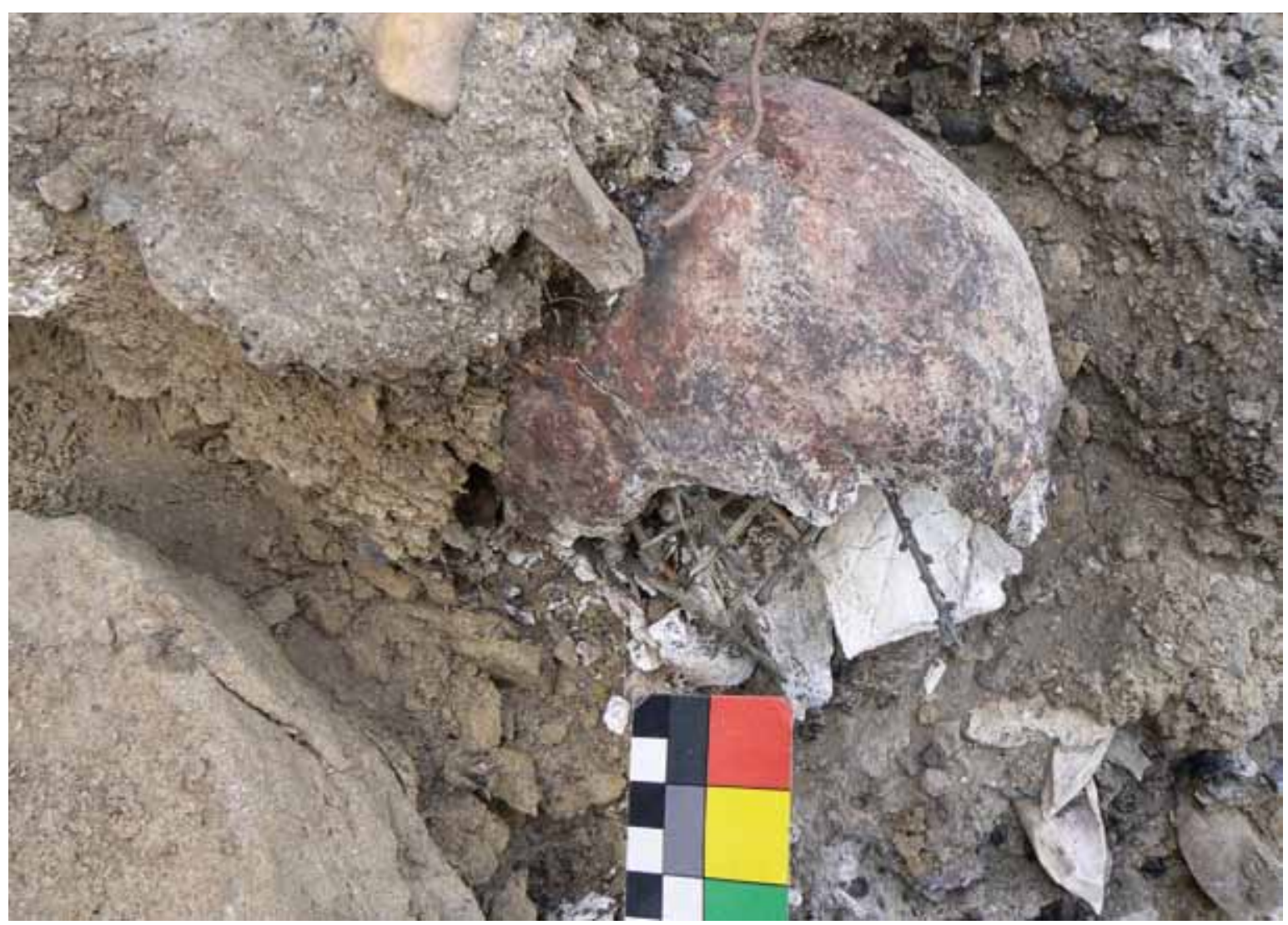

Figura 7. Río Bote 1. Vista sagital del cráneo del individuo J en el momento del hallazgo. Figure 7. Rí Bote 1. Saggital view of the cranium of individual J at the time of discovery. 


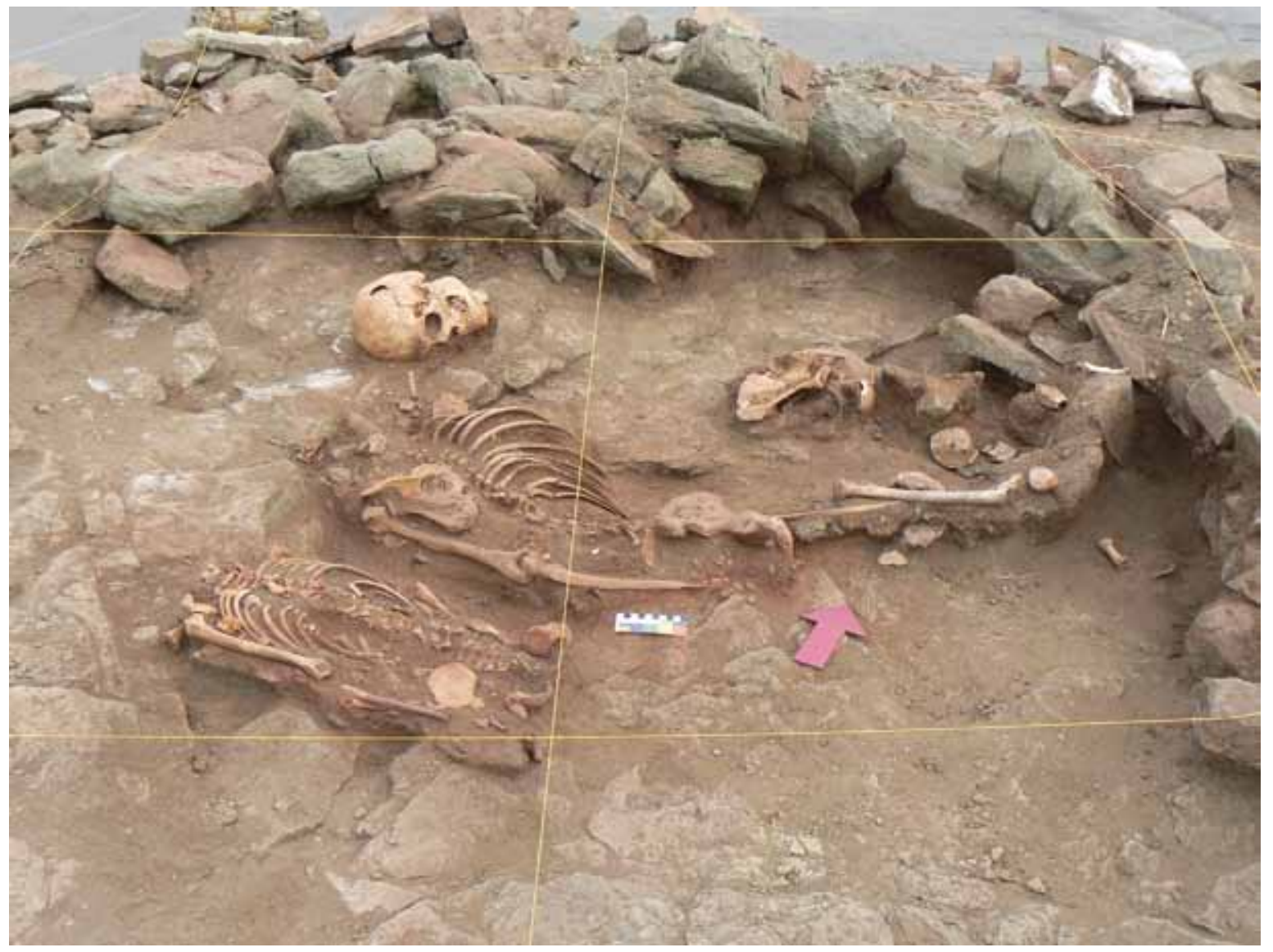

Figura 8. Huyliche 1, foto de planta con algunos de los esqueletos recuperados.

Figure 8. Huyliche 1, photo of burial site with some of the skeletons recovered.

En el caso de Río Bote 1, las muestras provenientes de sedimentos inmediatamente adyacentes a los restos esqueletarios de los individuos $\mathrm{H}$ e I tenían una concentración de 5\% de hidróxidos y óxidos de hierro. En el caso del individuo $\mathrm{J}$, los sedimentos asociados a fragmentos de costillas carecían de hidróxidos y óxidos de hierro, en cambio la muestra de los sedimentos relacionados con el cráneo presentaba una concentración de 50\%.

En el caso de Huyliche 1, las tres muestras que tienen más de un $40 \%$ de óxidos e hidróxidos de hierro corresponden tanto a sedimentos asociados con los individuos como a muestras que se encuentran entre rocas o fuera de la estructura rocosa. Las muestras que presentan una concentración de óxidos e hidróxidos entre $25 \%$ y $15 \%$ se encontraban en la capa superficial, entre las rocas de la estructura.

Los resultados de estos análisis apuntan a la diferente forma de aplicación de pigmentos, estando en el caso de Río Bote 1 asociado a los individuos, mientras que en el de Huyliche 1 habría sido aplicado sobre la estructura de rocas, sedimentos y a los individuos.
Los análisis de difracción de rayos X

Se estudiaron, aplicando este método, muestras de sedimentos adyacentes y alejados de los restos óseos, así como también muestras de material coloreado que se encontraba sobre los huesos, interpretado como probable pigmento.

\section{Río Bote 1}

\section{Individuo J}

En este caso se analizaron, por un lado, dos muestras de sedimento asociado a costillas y cráneo y, por otro, dos muestras de probables pigmentos adheridos al cráneo y a cuerpos vertebrales.

El sedimento asociado a las costillas (fig. 9) y al cráneo (fig. 10) de este individuo está compuesto por cuarzo, feldespatos, zeolitas, apatita, calcita, arcillas, hidroxilapatita, y hematita (óxido de hierro). En el material cercano al cráneo el pigmento es más abundante. 


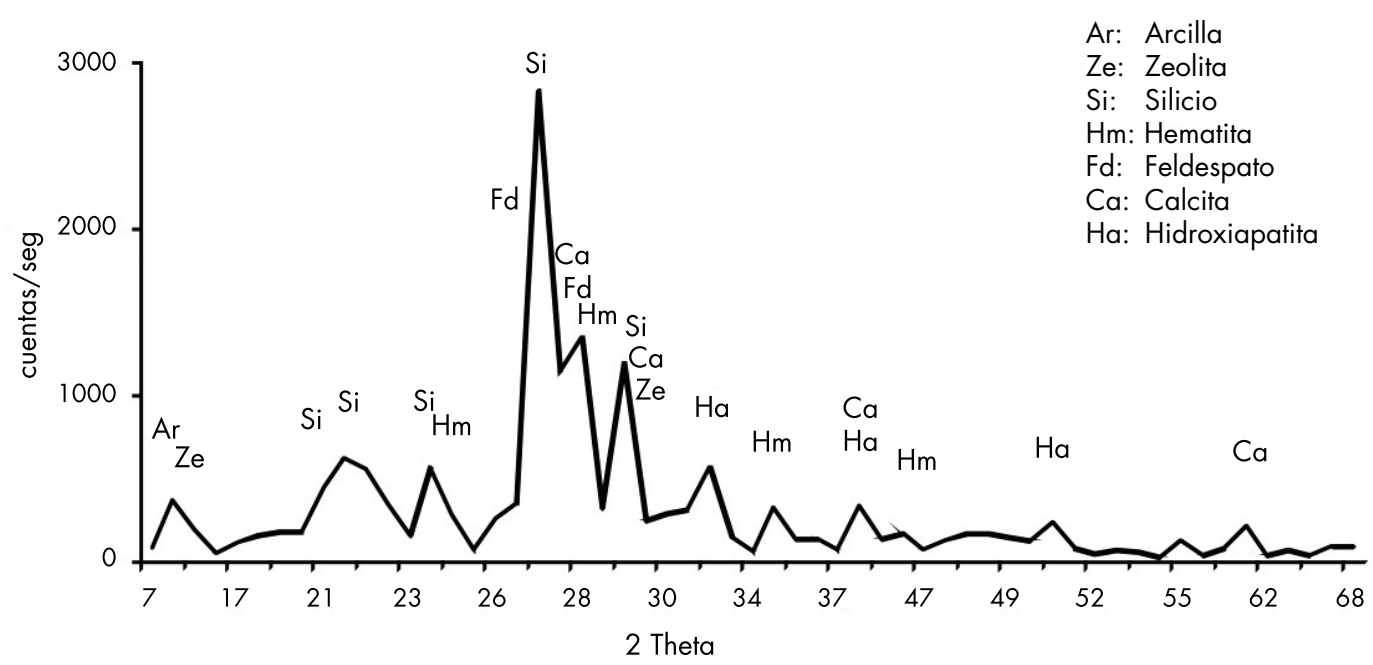

Figura 9. Diagrama de difracción de rayos X del sedimento asociado a las costillas correspondiente al individuo J.

Figure 9. X-ray diffractogram of sediment associated with the ribs of individual J.

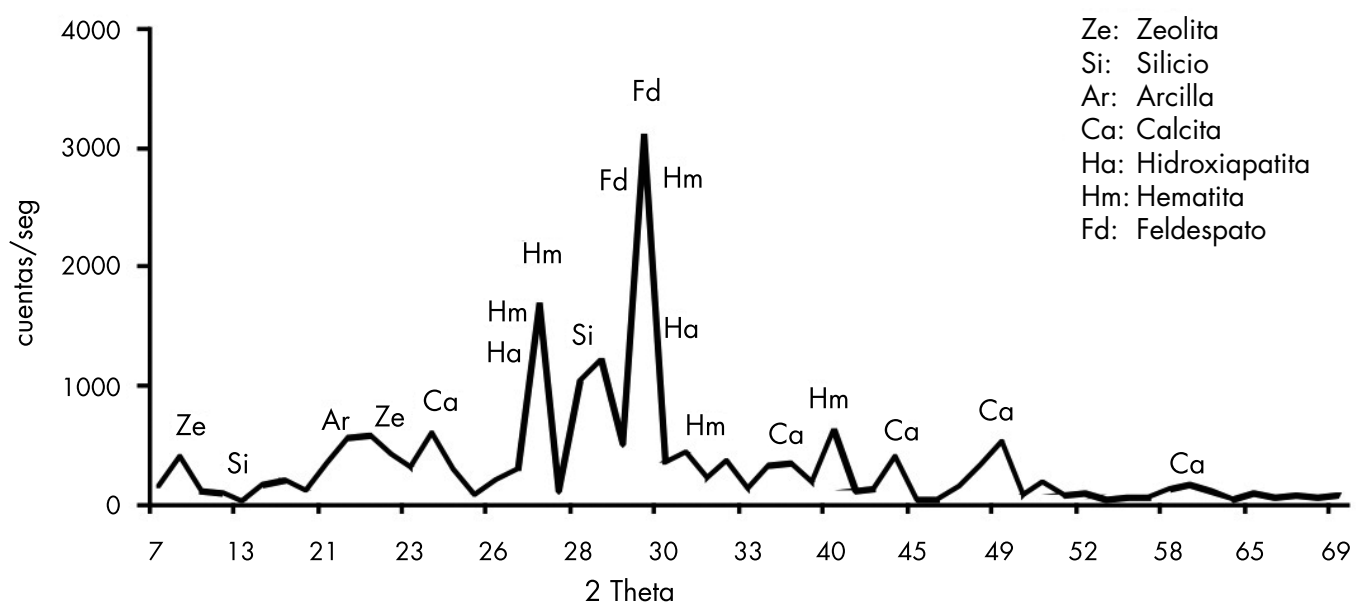

Figura 10. Diagrama de difracción de rayos X del sedimento asociado al cráneo correspondiente al individuo J.

Figure 10. X-ray diffractogram of sediment associated with the cranium of individual J.

En lo que se refiere a los probables pigmentos adheridos a este individuo, la muestra correspondiente al cráneo dio como resultado la presencia de hematita, yeso y feldespato de tipo albita (fig. 11), mientras que la muestra adherida al cuerpo vertebral evidenció la presencia de hematita (fig. 12), además de hidroxilapatita y calcita.

Individuo $\mathrm{H}$

El análisis de material de la clavícula dio como resultado la presencia de hidroxilapatita, goethita, vaterita, allofano, y fosfatos de hierro hidratados (fig. 13). Hidroxilapatita es el material componente de los huesos; vaterita, allofano y los dos fosfatos de hierro hidratados serían productos de la diagénesis. La goethita (óxido de hierro hidratado) es el compuesto colorante.
El sedimento extraído por debajo de la escápula izquierda contiene calcita, cuarzo, feldespato, yeso, zeolitas, hidroxiapatita y óxido de manganeso (fig. 14). No se evidencia en el difractograma la presencia de pigmento probablemente por la escasa cantidad presente (observada con lupa binocular).

Individuo I

$\mathrm{El}$ análisis de difracción de rayos $\mathrm{X}$ de un fragmento de diáfisis ósea dio como resultado la presencia de goethita e hidroxilapatita (fig. 15).

Por su parte, el sedimento asociado a ilion e isquion contiene feldespato, zeolitas, calcita, yeso, cuarzo, arcillas y hematita en reducida proporción (fig. 16). 


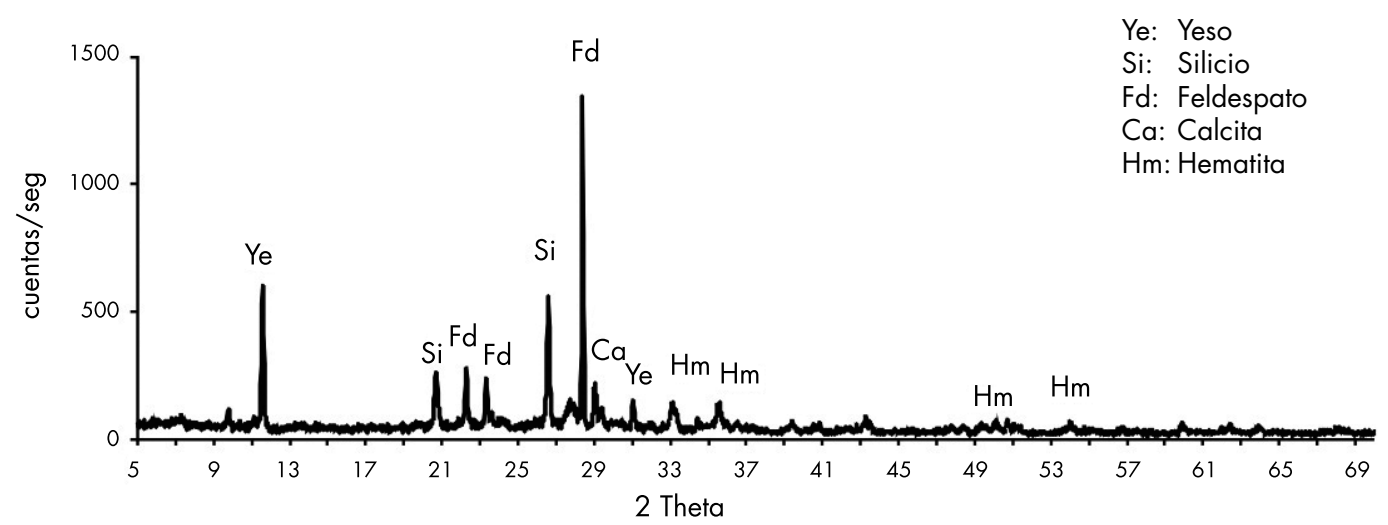

Figura 11. Diagrama de difracción de rayos X. Material adherido al cráneo del individuo J.

Figure 11. X-ray diffractogram of material adhering to the cranium of individual J.

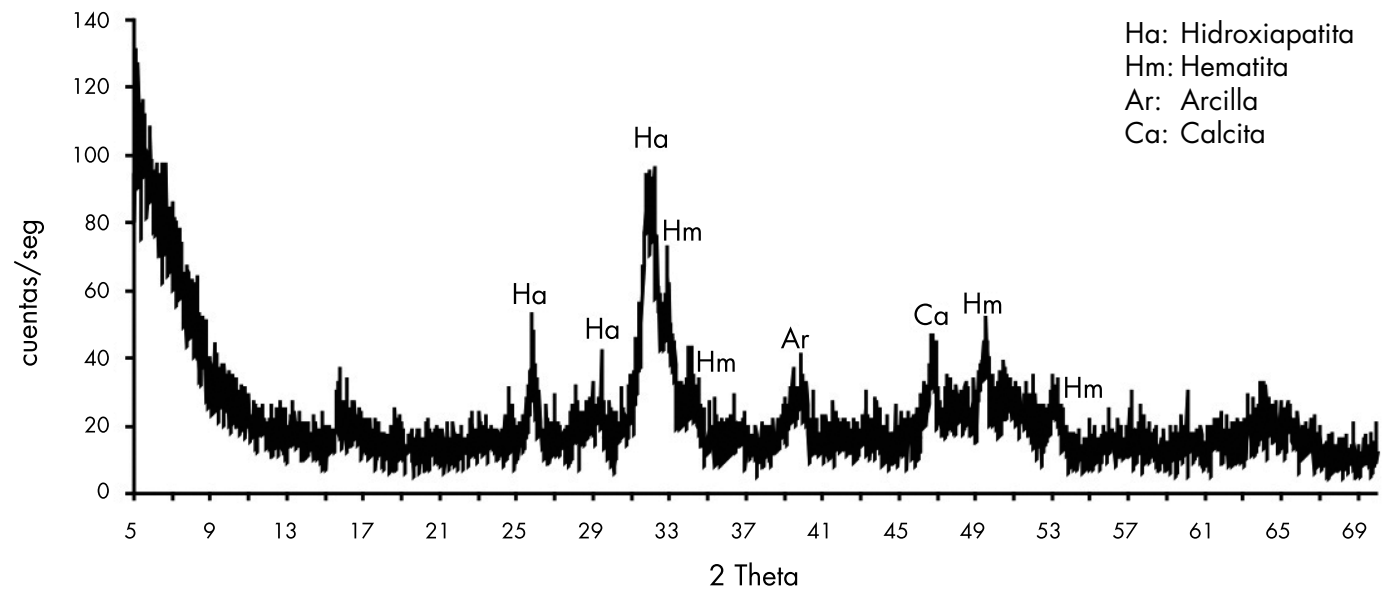

Figura 12. Diagrama de difracción de rayos X. Material adherido a cuerpo vertebral del individuo J.

Figure 12. X-ray diffractogram of material adhered to the vertebral body of individual J.

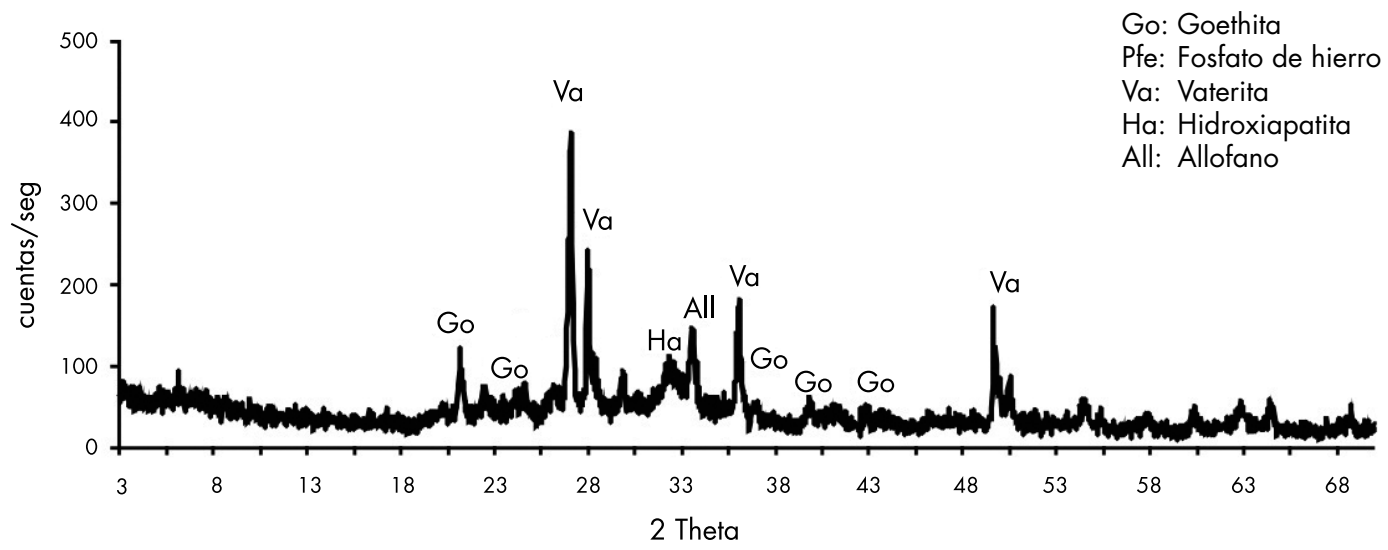

Figura 13. Difractograma de rayos X correspondiente a la clavícula izquierda del individuo $\mathrm{H}$.

Figure 13. X-ray diffractogram corresponding to the left clavicle of individual $\mathrm{H}$. 


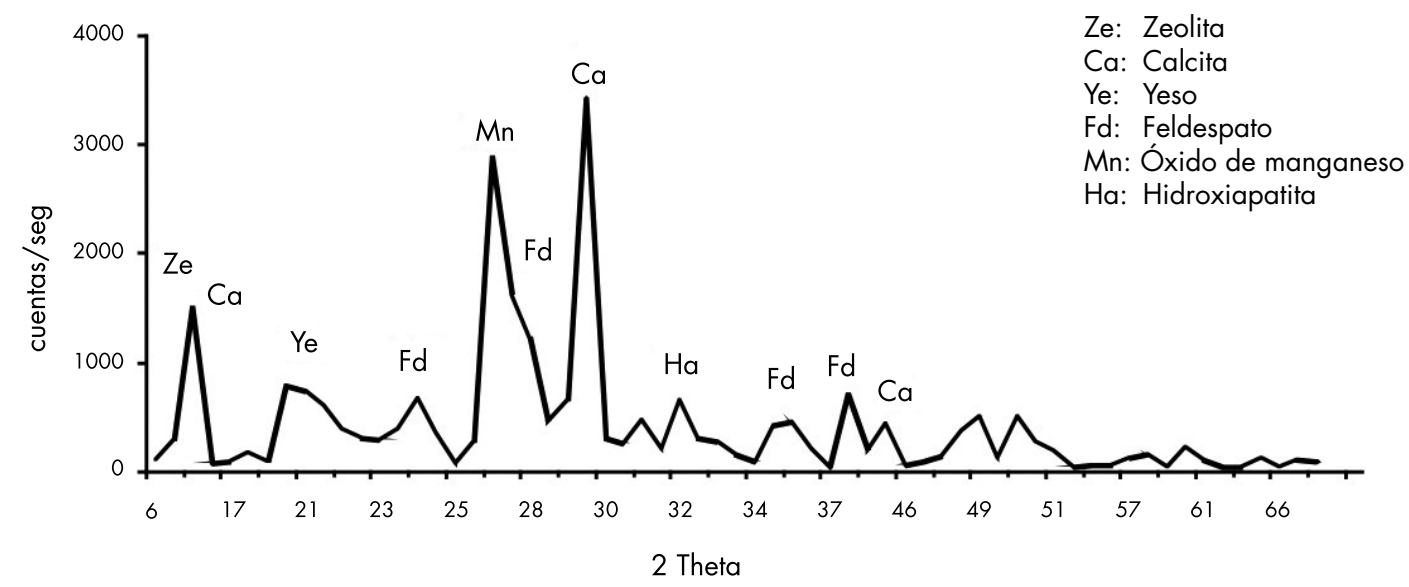

Figura 14. Difractograma de rayos X correspondiente al sedimento ubicado debajo de la escápula izquierda del individuo $\mathrm{H}$. Figure 14. X-ray diffractogram corresponding to the sediment located under the left scapula of individual $\mathrm{H}$.

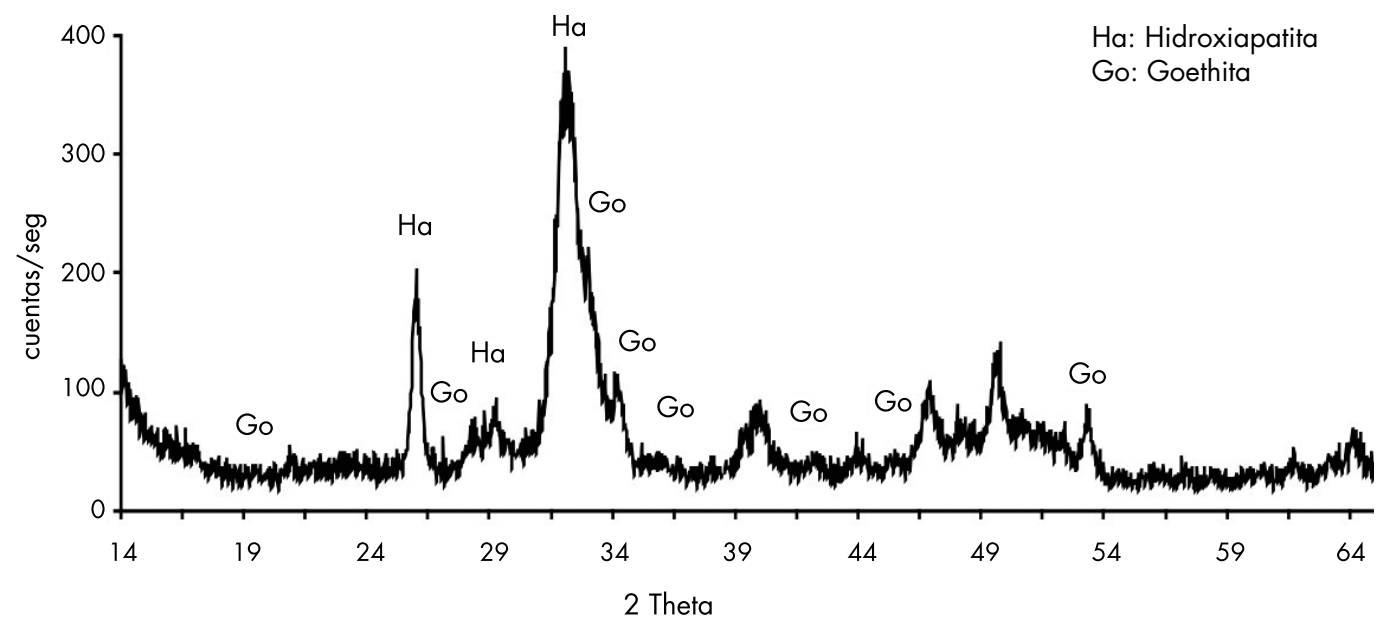

Figura 15. Difractograma de rayos X correspondiente al individuo I.

Figure 15. X-ray diffractogram corresponding to individual I.

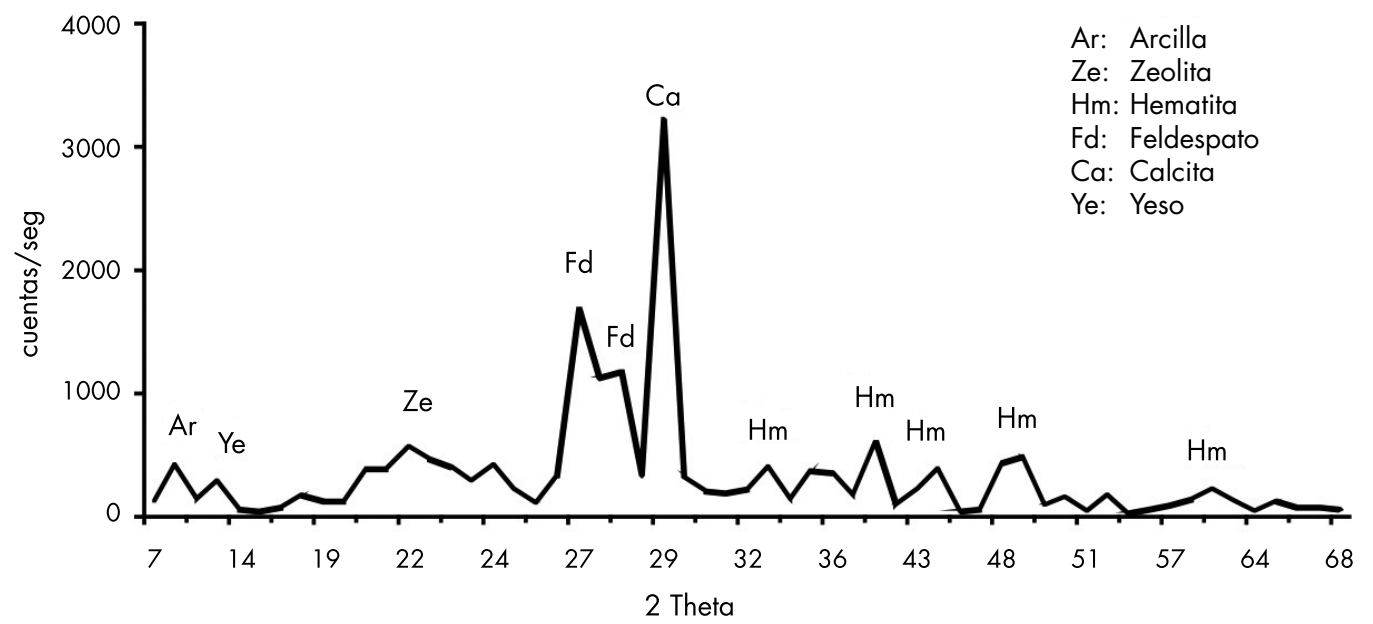

Figura 16. Difractograma de rayos X correspondiente a sedimento adyacente al individuo I. Figure 16. X-ray diffractogram of sediment found beside individual I. 


\section{Huyliche 1}

Como ya mencionamos, en este caso la presencia de pigmento es homogénea sobre toda la superficie de los huesos y solo se observó una concentración mayor en uno de los cráneos recuperados. En esta oportunidad no se realizaron análisis de difracción sobre los huesos, ya que, por las características de la presentación del material, su extracción afectaría una parte importante de la superficie ósea. A su vez, los fragmentos óseos no identificables no podían ser asignados a un individuo indiscutiblemente, ya que el entierro pudo haber sido reutilizado a lo largo del tiempo y podríamos caer en errores al asignar las muestras a un individuo al que no le corresponden.

El material sedimentario extraído de este sitio contiene pigmento hematita en cantidad variable, además de los componentes cuarzo, feldespatos, arcillas y zeolitas (figs. 17-21). Se analizaron muestras correspondientes a distintas profundidades dentro de la estructura funeraria.

\section{CONSIDERACIONES GENERALES}

Los análisis realizados sobre muestras procedentes de los dos entierros permiten observar diferencias en las formas de aplicar los pigmentos entre ca. 3700 y $400 \mathrm{AP}$ en la cuenca superior del río Santa Cruz, confirmando las observaciones realizadas en campo.

El primero de los casos corresponde a tres entierros realizados ca. $3740 \mathrm{AP}$, en un lugar utilizado recurrentemente con fines funerarios entre ca. 3800 y 3620 (cf. Franco et al. 2010). Los resultados de los análisis macroscópicos y de rayos X efectuados tienden a sustentar que los pigmentos fueron colocados exclusivamente sobre los cuerpos o que estuvieran envueltos en una sustancia orgánica que contuviera colorante. Esta afirmación se basa en la ausencia o muy baja presencia en sectores muy localizados en los sedimentos asociados (análisis con microscopio binocular y DRX), lo que haría que el colorante no se dispersara en el sedimento. Cabe señalar que los huesos de estos individuos presentan alteración térmica a más de $700^{\circ} \mathrm{C}$ (Montenegro et al. 2010), probablemente cuando todavía estaban presentes los tejidos blandos (Guarido 2013).

El otro caso analizado corresponde al entierro múltiple a cielo abierto bajo rocas (chenque) efectuado en el sitio Huyliche 1, datado en ca. 430 AP. Los estudios realizados (análisis macroscópicos, microscopio binocular y DRX) muestran que el pigmento se esparce tanto sobre los restos óseos como sobre las rocas que cubren el entierro y los sedimentos. No existen evidencias de alteración térmica.

Cabe mencionar que los estudios realizados no permiten establecer diferencias de composición entre los pigmentos utilizados en ambos sitios, ya que los análisis de difracción de rayos $\mathrm{X}$ indicaron la presencia de hematita y goethita. En el primer caso se trata de un óxido de hierro, mientras que el segundo es un hidróxido de hierro, el cual se logra a partir de la incorporación de agua en las moléculas, lo que puede ocurrir naturalmente en ambientes húmedos, como es el caso de Río Bote 1.

Los resultados obtenidos en estos dos sitios apuntan a sustentar la existencia de diferencias en la forma de inhumar a los muertos durante el Holoceno Tardío. A manera de síntesis estas se refieren a:

a) la selección de los lugares que se utilizan para las inhumaciones, con un cambio de la realización de los mismos en reparos bajo rocas a entierros al aire libre bajo rocas (chenque) (cf. Franco et al. 2010);

b) el abandono en la práctica de termoalteración de los restos humanos (Guarido 2013), y

c) el cambio en la forma de aplicación de los pigmentos, que pasan de ser utilizados directamente sobre los cuerpos -que probablemente fueron envueltos en material orgánico- a colocarlos tanto sobre los cuerpos como sobre los sedimentos adyacentes y rocas que cubren al mismo. En el último caso, la aplicación del pigmento se mantiene dentro de los límites del chenque.

Cabe recordar que, para los comienzos del Holoceno Tardío, formas de entierro similares a las existentes en Río Bote 1 han sido registradas hacia el sur, sugiriendo la existencia de redes sociales estables entre el río Santa Cruz y el estrecho de Magallanes entre $c a .3900$ y 3500 AP (Franco et al. 2011). En estos casos localizados más al sur (Orejas de Burro 1, Cerro Sota y Lago Sofía 1), también se describe la utilización de pigmentos como parte integral del entierro (Bird 1983, 1988; Prieto 1991; L'Heureux \& Barberena 2008; L'Heureux \& Amorosi 2010). En algunos de estos casos se ha registrado también la presencia de termoalteración, aunque solo se han efectuado observaciones macroscópicas (Bird 1983, 1988; Prieto 1991; L'Heureux \& Barberena 2008; L'Heureux \& Amorosi 2010).

Las semejanzas más cercanas para el final del Holoceno Tardío en la cuenca superior del río Santa Cruz, se limitan por ahora a ambas vertientes de la Sierra Baguales, en que se han encontrado entierros de tipo chenque en sectores elevados del paisaje. Resta hacer estudios más detallados a efectos de evaluar en 


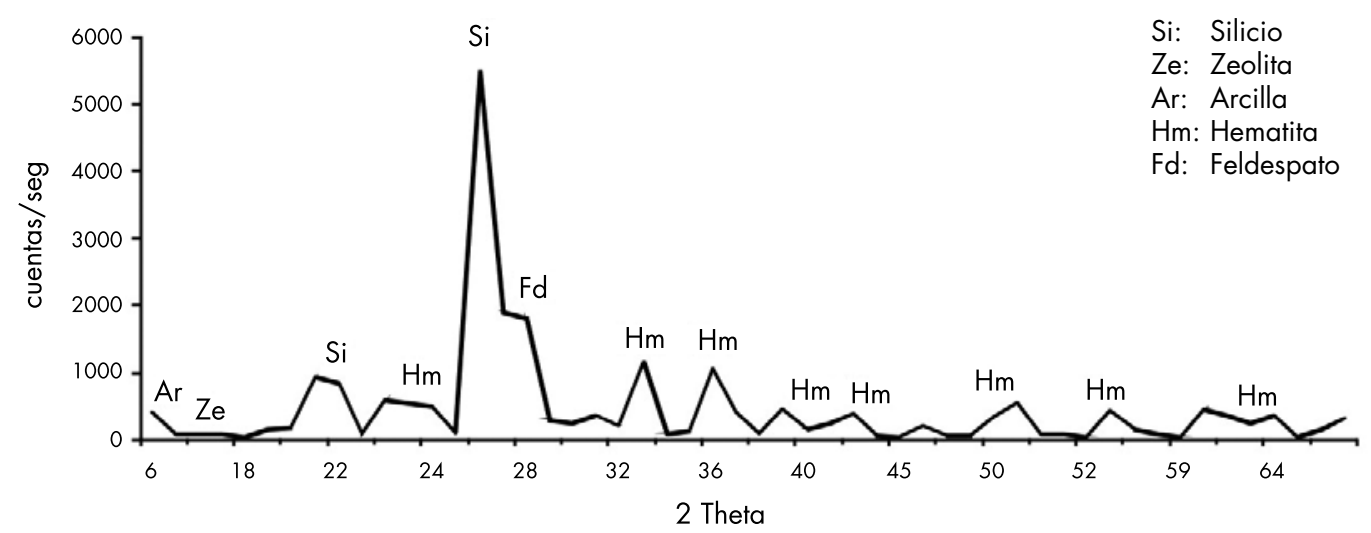

Figura 17. Difractograma de rayos X correspondiente a sedimento por debajo de rocas. Esta muestra estaba asociada a restos dispersos, uno de los cuales corresponde a un subadulto perinato.

Figure 17. X-ray diffractogram of sediment found under rocks. This sample is associated with dispersed buman remains, one of which corresponds to a perinatal subadult.

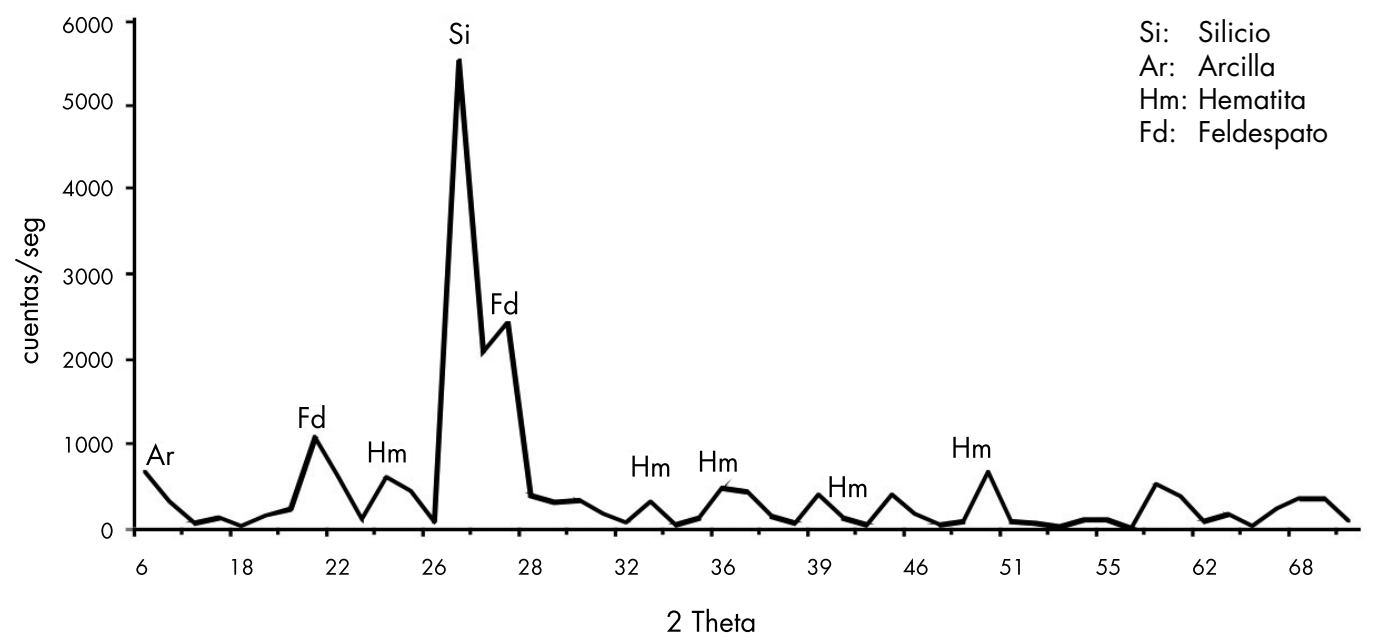

Figura 18. Difractograma de rayos X correspondiente a sedimento recuperado debajo de las rocas que formaban parte de la estructura del entierro en proximidad subadulto (individuo 1).

Figure 18. X-ray diffractogram of sediment recovered from underneath the rocks comprising the burial structure, near the subadult (individual 1).

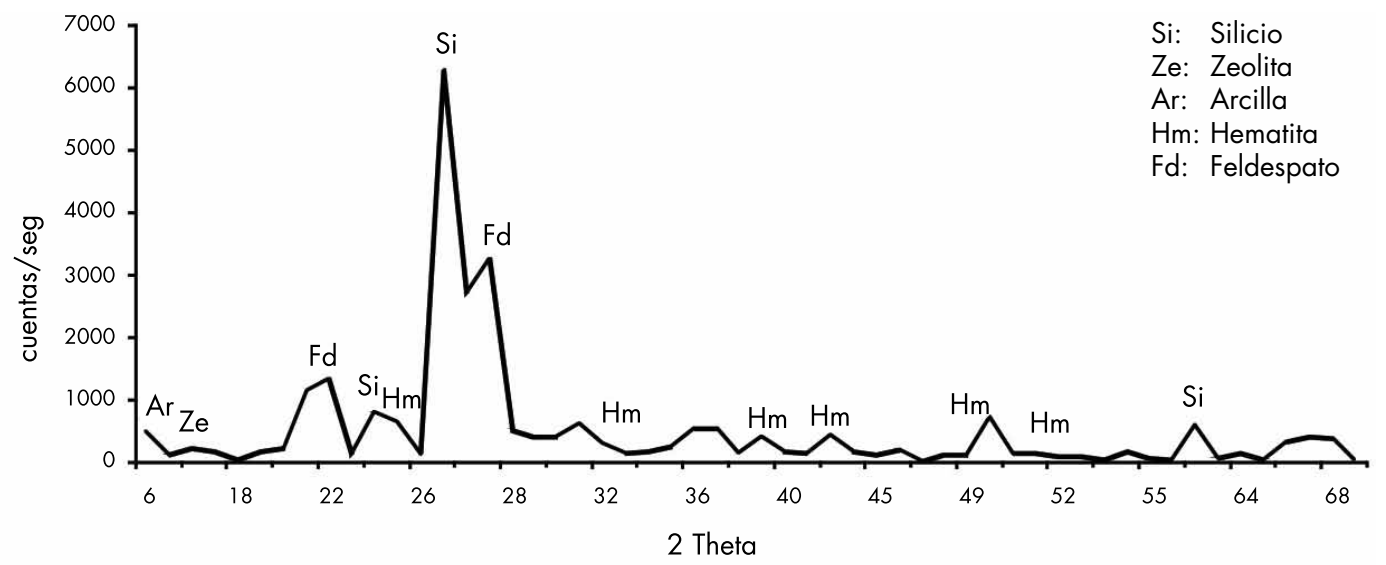

Figura 19. Difractograma de rayos X correspondiente a sedimento superficial correspondiente al entierro.

Figure 19. X-ray diffractogram of surface sediment from the burial site. 


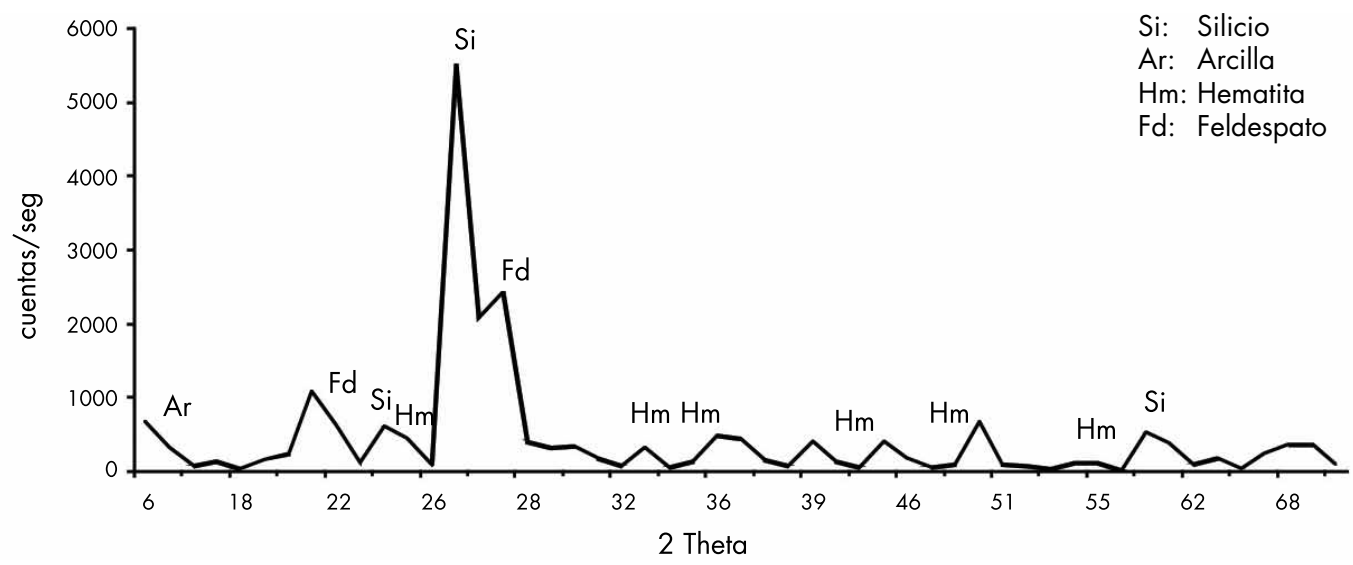

Figura 20. Difractograma de rayos X correspondiente a sedimento ubicado debajo de individuo 1 .

Figure 20. X-ray diffractogram corresponding to sediment located under individual 1.

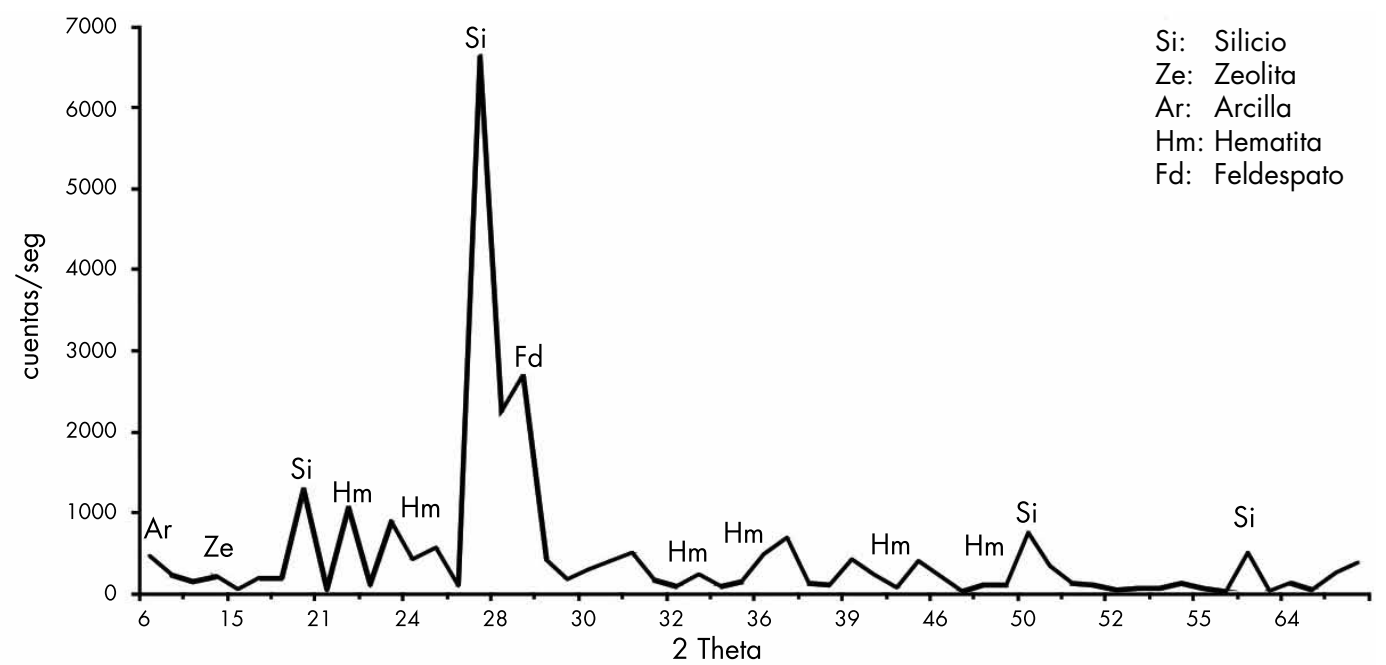

Figura 21. Difractograma de rayos X de sedimento en relación con la estructura del entierro. Figure 21. X-ray diffractogram of sediment related to the burial structure.

mayor profundidad las semejanzas existentes. Por el momento, los fechados son más tempranos al sur de la Sierra Baguales, debiendo señalarse que hasta el momento se posee un único fechado en Huyliche 1, estando en curso la realización de nuevas dataciones debido a la presencia de restos que se encuentran en posición desarticulada. En ambas vertientes de Sierra Baguales, el uso de colorante es abundante (Morano Büchner et al. 2009; Franco et al. 2010).

La suma de estos resultados tiende a sugerir, entonces, la existencia de un cambio en las prácticas funerarias en la cuenca superior del río Santa Cruz y espacios adyacentes hacia el sur, entre ca. 3600 y 400 AP. Entendemos que los análisis de las mismas, sumadas a otros referidos a los cambios en la forma de utilización de los espacios contribuirán a conformar una imagen más vívida del comportamiento de estos cazadores-recolectores.

RECONOCIMIENTOS Estos trabajos fueron realizados en el marco de los proyectos UBACYT 01/W404 y National Geographic 8397-08. Agradecemos a la Dirección de Patrimonio de la Provincia de Santa Cruz y a la Dirección de Cultura de la Municipalidad de Calafate. A la arquitecta Silvia Mirelman y a la Sra. Mariela Sabio. A los evaluadores anónimos cuyas sugerencias contribuyeron a mejorar este trabajo. Al dueño y personal de la estancia Río Bote. A Austral S. A. y a MIL Outdoor Adventure por el alojamiento brindado durante las tareas de campo. La empresa Austral construyó también la estructura necesaria para la excavación en el caso de Río Bote 1. A los pobladores locales, quienes dieron cuenta de la existencia de estos restos y colaboraron de distintas maneras en su recuperación. En particular, a Gerardo Povazsan, Berni Roil y Christian Soto. A todos los que participaron en los trabajos de campo. 


\section{NOTAS}

${ }^{1}$ Se denomina chenque a un cúmulo de piedras dispuestas en pila, creando una formación concéntrica en ciertos casos, bajo las cuales los indígenas depositaban restos humanos (Morano Büchner et al. 2009).

\section{REFERENCIAS}

Aguilera, N. \& P. Grendi, 1996. Hallazgo de un chenque protoaonikenk en Juni Aike, Magallanes. Anales del Instituto de la Patagonia 24: 163-175.

Bayliss, P.; D. C. Erd, M. E. Mroes, A. P. Sabina \& D. K. Smith, 1993. Mineral Powder Diffraction file. Compiled for the Joint Committee on Powder Diffraction Standard, in cooperation with the American Society for Testing and Materials. Swarthmore, Pa: JCPDS International Centre for Diffraction Data.

Belardi, J. B.; L. A. Borrero, P. Campan, F. Carballo Marina, N. V. Franco, M. F. García, V. D. Horwitz, J. L. Lanata, F. M. Martin, F. E. MuÑOZ \& F. SAVANTI, 1992. Archaeological Research in the Upper Santa Cruz Basin, Patagonia. Current Anthropology 33 (4): 451-454.

BIRD, J., 1983. Enterratorios paleoindios con cremación en las cuevas de Pali Aike y Cerro Sota en Chile meridional. Anales del Instituto de la Patagonia 14: 55-63.

— 1988. Travels and Archaeology in South Chile. Iowa: University of Iowa Press.

Borrero, L. A. \& N. V. Franco, 2000. Cuenca superior del río Santa Cruz: Perspectivas temporales. En Desde el país de los gigantes. Perspectivas arqueológicas en Patagonia, tomo II, pp. 345-356. Río Gallegos: Unidad Académica Río Gallegos de la Universidad Nacional de la Patagonia Austral.

Franco, N. V., 2002. Estrategias de utilización de recursos líticos en la cuenca superior del río Santa Cruz. Tesis doctoral inédita Facultad de Filosofía y Letras, Universidad de Buenos Aires, Buenos Aires.

— 2004. Rangos de acción, materias primas y núcleos preparados al sur de Lago Argentino. En Contra viento y marea. Arqueología de la Patagonia, M. T. Civalero, P. Fernández \& A. G. Guráieb, Comps., pp. 105-116. Buenos Aires: Instituto Nacional de Antropología y Pensamiento Latinoamericano y Sociedad Argentina de Antropología.

— 2008. La estructura tecnológica regional y la comprensión de la movilidad humana: Tendencias para la cuenca del río Santa Cruz. En Arqueología del extremo sur del continente americano, L. A. Borrero \& N. V. Franco, Comps., pp. 119154. Buenos Aires: Consejo Nacional de Investigaciones Científicas y Técnicas, Instituto Multidisciplinario de Historia y Ciencias Humanas.

Franco, N. V.; L. A. Borrero, J. B. Belardi, F. Carballo Marina, F. M. Martin, P. Campan, C. Favier Dubois, N. Stadler, M. I. Hernández, H. Cepeda, A. S. Muñoz, F. Borella, F. MuÑoz \& I. Cruz, 1999. Arqueología del Cordón Baguales y sistema lacustre al sur del Lago Argentino. Praehistoria 3: 65-86.

Franco, N. V.; A. L. Guarido, S. García Guráieb, M. Martucci \& M. OCAMPo, 2010. Variabilidad en entierros humanos en la cuenca superior y media del río Santa Cruz (Patagonia, Argentina) En Actas del XVII Congreso Nacional de Arqueología Argentina, Tomo V, pp. 1901-1906, Mendoza.

Franco, N. V.; N. Cirigliano \& P. Ambrústolo, 2011. Semejanzas en tecnologías, diseños y prácticas funerarias al sur de la cuenca superior del río Santa Cruz: Algunos ejemplos correspondientes al Holoceno Tardío. En Bosques, montañas y cazadores: Investigaciones arqueológicas en Patagonia Meridional, L. A Borrero \& K. Borrazzo, Eds., pp. 155-178. Buenos Aires: Instituto Multidisciplinario de Historia y Ciencias Humanas (CONICET).
Gómez Otero, J., 1991. Cazadores tardíos en la zona fronteriza del paralelo 52 Sur. I. El paraje de Juni Aike. Anales del Instituto de la Patagonia 19: 47-71.

GuARIDO, A. L., 2013. Alteración térmica en restos humanos fechados en ca. 3740 años AP en el sitio Río Bote 1. En Tendencias teórico-metodológicas y casos de estudio en la arqueología de la Patagonia, A. F. Zangrando, R. Barberena, A. Gil, G. Neme, M. Giardina, L. Luna, C. Otaola, S. Poulides, L. Salgán \& A. Tívoli, Eds., pp. 397-404. Buenos Aires: Museo de Historia Natural de San Rafael, Sociedad Argentina de Antropología e Instituto Nacional de Antropología y Pensamiento Latinoamericano.

L'HEUREUX, G. L. \& R. BARBERENA, 2008. Evidencias bioarqueológicas en Patagonia meridional: El sitio Orejas de Burro 1 (Patagonia, Provincia de Santa Cruz). Intersecciones en Antropología 9: 11-24.

L'Heureux, G. L. \& T. Amorosi, 2010. El entierro de Cerro Sota (Magallanes, Chile) a más de setenta años de su excavación. Magallania 38 (2): 133-149.

MarTinic, M., 1976. Hallazgo y excavación de una tumba aonikenk en Cerro Johnny ("Brazo Norte"), Magallanes. Anales del Instituto de la Patagonia 7: 87-94.

MASsONE, M., 1996. Hombre temprano y paleoambiente en la región de Magallanes: Evaluación crítica y perspectivas. Anales del Instituto de la Patagonia (Ser. Cs. Hs.) 24: 81-98.

Massone, M.; A. Prieto \& P. Cárdenas, 1985-1986. Contexto arqueológico de un enterratorio tehuelche excavado en la localidad de san Gregorio, Magallanes. Anales del Instituto de la Patagonia 16: 95-101.

Mehr, A. \& N. V. Franco, 2009. Cambios en la morfología de los reparos rocosos: El caso de los sitios arqueológicos Chorrillo Malo 2 y Río Bote 1 (Provincia de Santa Cruz, Argentina). En Arqueología de Patagonia: Una mirada desde el último confin, tomo 2, M. Salemme, F. Santiago, M. Álvarez, E. Piana, M. Vázquez \& M. Mansur, Comps., pp. 893-900. Ushuaia: Editorial Utopias.

Montenegro, T.; A. L. Guarido \& N. V. Franco, 2010 Ms. ¿̨Combustión en entierros humanos a comienzos del Holoceno Tardío en la margen sur del río Santa Cruz (Patagonia, Argentina)?

Morano Büchner, S.; V. Sierpe González \& A. Prieto Iglesias, 2009 Rescate del Chenque Cerro Guido. En Arqueología de Patagonia: Una mirada desde el último confín, tomo 2, M. Salemme, F. Santiago, M. Álvarez, E. Piana, M. Vázquez \& M. Mansur, Comps., pp. 661-668. Ushuaia: Editorial Utopias.

Prieto, A., 1991. Cazadores tempranos y tardíos en Cueva del lago Sofía 1. Anales del Instituto de la Patagonia 20: 75-99.

- 1993-1994. Algunos datos en torno a los enterratorios humanos de la región continental de Magallanes. Anales del Instituto de la Patagonia 22: 91-100.

REYEs, O., 2002. Funebria indígena en el curso inferior del valle del río Ibañez, margen occidental de la estepa centropatagónica (XI Región de Aisén). Anales del Instituto de la Patagonia. 30: 87-101.

Salvarredy, A. \& A. L. Guarido, 2012. Análisis de la composición de sexo y edad de un nuevo entierro múltiple datado en $c a$. 3740 años en la cuenca superior del río Santa Cruz. En Entre pasados y presentes III. Estudios contemporáneos en ciencias antropológicas, N. Kuperszmit, T. Lagos Mármol, L. Mucciolo M. Sacchi, Comps., pp. 526-537. Buenos Aires: Mnemosyne.

Stine, S., 1994. Extreme and persistent drought in California and Patagonia during Medieval Time. Nature 369: 546-549.

Stine, S. \& M. Stine, 1990. A record from Lake Cardiel of climate change in Southern South America. Nature 345: 705-708.

Symes, S. A.; C. W. Rainwater, E. N. Chapman, D. R. Gipson \& A. L. PIPER, 2008. Patterned thermal destruction of human remains in a forensic setting. En The analysis of burned buman remains, C.W. Schmidt \& S. A. Symes, Eds., pp. 15-54. Londres: Academic Press.

Tessone, A.; F. Sangrando, G. Barrientos, S. Valencia, H. Panarello \& R. GoÑı, 2005. Isótopos estables del carbono en Patagonia meridional: Datos de la cuenca del lago Salitroso (provincia de Santa Cruz, República Argentina). Magallania 33 (2): 21-28. 
